\title{
ENTRE EL ORGANISMO Y EL ARTEFACTO. \\ SOBRE LA CONFORMIDAD A FIN NARRATIVA
}

\section{BETWEEN THE ORGANISM AND THE ARTIFACT. REGARDING CONFORMITY TO THE NARRATIVE END}

\author{
GERMÁn GARrido MiÑAMBres* \\ Universidad Complutense de Madrid
}

Resumen: El principio de conformidad a fin proporciona a Kant el medio para justificar la contingente adecuación de la naturaleza en sus leyes mecánicas a las limitaciones del entendimiento humano. Considerando que la narración literaria persigue la recreación de un mundo a través de la unidad de experiencia, el presente artículo sostiene que es en la idea de conformidad a fin formal donde encuentra el concepto de fin que le corresponde. La Crítica del Juicio, y especialmente la Primera Introducción, permite dar cuenta de la múltiples implicaciones que conlleva la traslación de este principio a un entorno ficcional como el narrativo.

Palabras clave: Crítica del Juicio, Conformidad a fin, Literatura, Narración, Pirandello.

Авsтract: The principle of conformity to an end provided Kant with the means to justify the contingent suitability of the mechanical laws of nature to the limitations of human understanding. Considering that literary narration pursues the recreation of the world through the unity of experience, this article holds that it is in the idea of conformity to a formal end that Kant finds the concept of end that corresponds to this. The Criticism of Judgment, particularly the First Introduction, makes it possible to realize the multiple implications involved in the movement of this principle to a fictional context such as narration.

KEY wOrDs: Criticism of Judgment, Conformity to an end, Literature, Narrative, Pirandello.

*gegarrid@pdi.ucm.es 


\section{Introducción}

Matías Pascal inicia el relato de sus aventuras confesando que durante largo tiempo demoró su proyecto de escritura por considerar esta una ocupación superflua. La culpa de ello, explica el personaje de Pirandello a su interlocutor, el archivero Pellegrinotto, como de tantas otras cosas, fue en realidad de Copérnico. No en vano, el descubrimiento de que la tierra es sólo un astro más que gira en la inmensidad del cosmos privó de toda relevancia a los hechos humanos volviendo por ende frívola e insustancial su relación pormenorizada. Arrojado a un universo insondable, la crónica de sus actos devino una vana pantomima, una fruslería que no merece ni el esfuerzo del narrador ni la atención de su destinatario. Las dudas que Matías Pascal expone al comienzo del relato no atañen sin embargo solo a la relevancia de la obra poética tras la derogación del sistema ptoloneico. Aunque esa insignificancia sigue en efecto a la del hombre en un universo de cuyo centro ha sido arrojado, el sentido del giro copernicano va como es sabido más allá del literal desplazamiento cosmológico. Su traslación epistemológica supone ante todo el abandono de la confianza en que el mundo esté sometido a un orden que puede ser desentrañado por la razón. Si la narración deja de ser pertinente una vez se ha producido este giro es porque ella misma descansa sobre el presupuesto de que en efecto es posible supeditar el caótico magma de la experiencia a su comprensión como todo unitario. Pascal no está pues lamentando solo la futilidad del ejercicio literario, sino que además constata la imposibilidad de amoldar sus vivencias a un conjunto dotado de sentido en un mundo que ha dejado de tenerlo. Sucede sin embargo, como señala Pellegrinotto, que el hombre no puede mantener largo tiempo el recuerdo de su pequeńez y del insignificante lugar que ocupa su mundo. Nada atestigua mejor la evidencia de ese olvido en su quehacer diario que su obrar, entendido este no ya como mero actuar, sino como la realización de obras, esto es, como el planear y llevar a cabo algo conforme a un fin. Ignorando el movimiento de traslación al que está sometida su morada en la tierra, el hombre fabrica utensilios, cultiva la tierra, construye carreteras, edifica catedrales, y, además, escribe libros. Ese obrar no parte sólo del momento irreflexivo que dicta el imperio de la costumbre, como parece sugerir Pellegrinotto: algo en el hombre le mueve a seguir contemplando la naturaleza como si hubiera sido organizada para conformarse a su entendimiento, como si ella misma fuera también el producto artístico de una voluntad superior.

Del mismo modo, si algún misterioso designio vincula el fin de la naturaleza como creación divina con el del libro como creación humana salta a la vista que, como no deja de recordar Pellegrinotto a Matías Pascal, el cuestionamiento del 
primero estuvo lejos de poner en peligro el oficio de la escritura. La invención de la imprenta primero y el progresivo abaratamiento de los soportes editoriales más adelante, otorgó al libro un inusitado grado de difusión como producto de consumo. La forma literaria más beneficiada por esta revolución mediática fue precisamente aquella que permite referir una vivencia como conjunto de hechos organizados en relación a un fin. La novela de Pirandello apunta de este modo al fundamento común que presupone el conocimiento del mundo y su fijación narrativa: la misteriosa circunstancia que nos lleva a aguardar de la naturaleza una disposición a ser abarcada como unidad por la razón, o, conforme a la formulación que hace Kant en la primera introducción a la Crítica del Juicio, a que la experiencia se organice "como sistema y no como mero agregado" (XX 209) ${ }^{1}$. Kant localiza como es sabido el elemento que propicia el enlace entre el potencialmente ingobernable ámbito de la materia sensible y los conceptos de la razón en el principio trascendental de la conformidad a fin $(Z w e c k m a ̈ ß i g k e i t)^{2}$. La narración por su parte debe asumir la posibilidad de esa correspondencia aunque al reproducirla transforme necesariamente su alcance y significado: como producto de arte diseñado por una voluntad particular, el texto despierta en su destinatario la expectativa de estar organizado conforme a un propósito como no lo hace la naturaleza. Pero al mismo tiempo la narración aspira a producir en el lector el efecto de lo inmotivado, de lo que espontáneamente surge hasta configurar la totalidad de una experiencia. Si el principio kantiano de la conformidad a fin resulta particularmente revelador para iluminar esta problemática es porque atańe también a la doble condición del texto como artefacto construido por una conciencia y como creación de las bellas artes que pretende pasar por una segunda naturaleza (Kuyters 22-27 y 119-136). Las múltiples acepciones que la conformidad a fin recibe en la Critica del Juicio, y muy especialmente en la primera "Introducción», permiten en definitiva replantear las relaciones entre ficción y realidad que conforman los límites y posibilidades del universo narrativo.

\section{La conformidad a fin entre el organismo y el artefacto}

Siendo el principio a priori del Juicio lo que compromete el vínculo entre la comprensión de la naturaleza y su representación artística resulta forzoso remitir-

${ }^{1}$ Las referencias a las obras de Kant siguen la edición de la Akademie-Ausgabe, indicando entre paréntesis volumen y páginas. Las citas traducidas de la Primera Introducción siguen la versión de Nuria Sánchez Madrid (2011), las de la Crítica el Juicio la de Miguel Morente.

2 Se ha optado en todos los casos por traducir Zweckmäßigkeit como «conformidad a fin» en lugar de como «finalidad». 
se siquiera someramente a su génesis y necesidad dentro del sistema kantiano. Esa necesidad queda claramente expresada en el ya mencionado cuarto apartado de la introducción original, donde se esboza la temible posibilidad de que el hombre debiera abrirse paso en el conocimiento mundo sin la confianza de que este termine adecuándose a la unidad sistemática demandada por la razón. De poco nos serviría ser capaces de reconocer determinados objetos empíricos o probar la validez de ciertas leyes mecánicas si no pudiéramos presuponer que todos esos objetos y leyes convergen en una totalidad de sentido que responde al concepto de naturaleza o, dicho de otro modo, sin conceder a esa serie de fenómenos la posibilidad de ajustarse a un principio organizativo. Con todo lo que tienen de fabulosos o incongruentes, los paisajes a los que nos acostumbran los géneros de la ciencia ficción o lo fantástico mantienen la potencial adecuación a un orden explicativo que permite su exploración por parte del lector. Como demuestra el innombrado protagonista del cuento El extraño de Loveccraft también nuestra realidad puede adoptar la apariencia de lo inaudito o lo monstruoso sin por ello perder el nexo relacional de su constitución interna. No son solo las categorías de espacio, tiempo o causalidad (frecuentemente alteradas en esta clase de literatura) lo que presupone la indagación de esos mundos alternativos, sino la idea de que su alteridad no excluye una posible sujeción al principio de unidad impuesto por las condiciones de la experiencia.

Así pues, que el Juicio medie entre los conceptos del entendimiento y la materia sensible no garantiza en absoluto que pueda dar lugar a una comprensión unitaria de la naturaleza, como ya se hace patente en el papel que desempeña esta facultad en la Crítica de la razón pura. Recordemos que la "Analítica de los Principios» se ocupa de proporcionar al Juicio el procedimiento para la aplicación de los conceptos a las intuiciones así como para la subsunción de fenómenos concretos en leyes generales. El cometido del juicio en su función determinante no es por lo tanto otro que el de sensibilizar los conceptos del entendimiento o, como se reitera en el $\$ 44$ de la Antropología, el de descubrir lo particular que corresponde a lo universal para hacer así posible el conocimiento de objetos. Este juicio determinante se limita sin embargo a estipular los presupuestos que rigen la esquematizacion de las categorías en las formas puras de la intuición, pero nada acierta a señalar sobre la posibilidad de que los fenómenos así subsumidos por el entendimiento se dejen organizar en una unidad general de sentido, en un haz coherente de relaciones que a su vez estipule el lugar que ocupan como entidades individualizadas. Dicho de otro modo, aunque el juicio determinante permite explicar la producción de imágenes por las cuales un objeto es reconocido o un fenómeno se deja adscribir a una regla, no asegura en modo alguno que nuestra 
experiencia refrende el vínculo de lo así aprehendido por el conocimiento sensible a una misma idea o principio aglutinador: el esquematismo da cuenta de las condiciones que propician la intelección de objetos particulares, mas no de la común participación de estos en un universo ordenado.

La razón, sin embargo, exige precisamente la unidad completa de los conocimientos alcanzados por el entendimiento. Pero dada, la estricta separación que la Crítica exige a los ámbitos del entendimiento y la razón, no hay forma de que el Juicio pueda aplicar los conceptos de esta a las intuiciones sin incurrir en la falacia del dogmatismo. La «Dialéctica» se ocupará sin embargo de aclarar que los conceptos de la razón pueden ser indirectamente relacionados con las intuiciones a través del entendimiento, de tal modo que, si bien no cabe esperar que funcionen como principios constitutivos de la experiencia empírica, si es lícito darles un uso regulativo que permita organizarla (Luján 127). Así empleados, los conceptos de la razón no determinan nada acerca de los fenómenos, limitándose a habilitar la posibilidad de su legítimo uso. Ahora bien, nada en absoluto garantiza que la organización lógica de los conocimientos avanzada por el Juicio corresponda en efecto al sistema por el que se organizan los fenómenos naturales; nada tampoco que las potencialmente infinitas leyes empíricas se dejen aprehender en un sistema abarcable por el entendimiento. Como termina de hacerse explícito en el "Apéndice a la Dialéctica», el Juicio necesita presuponer sin embargo esa homogeneidad entre organización lógica y correlato empírico. Debe asumir no solo la función ordenadora de los conceptos de la razón sino la necesidad de que la naturaleza, merced a una misteriosa disposición, se especifique efectivamente en un sistema de géneros y especies para facilitar su comprensión unitaria, (III 432 y ss.). No es que el Juicio pretenda con ello que la naturaleza se organice objetivamente conforme a ese orden ni sostenga la existencia de una voluntad que la haga posible. Simplemente constata la correspondencia entre la exigencia uniformizadora que plantean las ideas de la razón y el ámbito de lo contingente como necesaria condición que anticipa toda forma de conocimiento. Pues de no poder asegurarse esa correspondencia no es solo el quehacer del investigador de la naturaleza, sino todo el edificio de la Crítica lo que se vendría abajo. Tras haber proporcionado en la "Dialéctica» las pautas para el correcto uso de los conceptos de la razón por parte del Juicio, la Crítica de la razón pura se cierra sin haber llegado a demostrar qué fundamenta la confianza en un aparentemente improbable acuerdo entre el orden que la razón demanda a la naturaleza y lo que el conocimiento empírico de esta puede llegar a constatar. Será precisamente ese fundamento lo que Kant localice en el principio trascendental de la conformidad a fin introducido en la Crítica del Juicio. 
La obra de 1789 nace por lo tanto con la necesidad de demostrar la existencia de una tercera facultad que propicie el pleno tránsito entre entendimiento y razón. Para asegurar su autonomía esa facultad precisa de su propio principio a priori, cuyo descubrimiento atestigua una célebre carta a Reinhold del 28 de diciembre de 1787 (Sánchez Madrid 292-293). Lamentablemente, definir con exactitud los diferentes sentidos que la conformidad a fin recibe a lo largo de la Crítica del Juicio es cualquier cosa menos sencillo y escapa a las pretensiones de un texto como este (ver al respecto la clarificadora exposición en Duque 125-147). Baste tener en cuenta que, en su ya clásico artículo, Giogio Tonelli (1958) propone nada menos que nueve esquemas para abarcar las variantes y acepciones que este concepto conoce durante la gestación de la tercera crítica. Pues, en efecto, es preciso tener también en cuenta la perspectiva diacrónica para contextualizar convenientemente su significado. Aunque nuestro propósito es centrarnos en la Primera Introducción, Tonelli recuerda que tanto la "Analítica del juicio estético», con sus célebres cuatro momentos, como la "Dialéctica», que incluye la mayoría de referencias explícitas a la belleza artística y literaria, preceden cronológicamente a la redacción de este texto ${ }^{3}$. Así pues, la conformidad a fin es primero tratada en relación al juicio sobre lo bello, circunstancia que no es ajena al hecho de que Kant planteara inicialmente como una crítica del gusto la obra que terminaría dando cuenta de una nueva facultad del conocimiento ${ }^{4}$. Ignorando momentáneamente esta circunstancia partiremos de la primera mención que se hace de este concepto en la Introducción como «única regla originalmente oriunda del juicio».

En efecto, si el entendimiento proporciona las condiciones generales que hacen posible el conocimiento sensible y la razón las que facultan el de lo inteligible, el Juicio queda privado de un ámbito propio de aplicación y su legislación se circunscribe a aquello que propicia la subsunción de los fenómenos sensibles en las ideas de la razón. Pues una cosa es que la experiencia se deje sistematizar conforme a las leyes trascendentales del entendimiento y otra muy distinta que lo haga también de acuerdo con las leyes empíricas. La subsunción de lo particular bajo lo universal que implica todo juicio sintético sobre objetos empíricos (X es una planta, un mamífero, un vertebrado etc...) conlleva sin embargo la necesidad de que la experiencia empírica, desafiando la potencial infinitud de sus leyes, se deje supeditar a un orden. El Juicio precisa en definitiva que la naturaleza nos

3 Tonelli destaca además el uso que de este concepto se hace en un texto contemporáneo al inicio de la "Analítica de lo bello", Sobre el uso de los conceptos teleológicos en la filosofia.

4 Sobre la compleja génesis de la Tercera Crítica ver también Dumouchel (1999 y 1998) y Zammito (1992). 
conceda el favor (Gunst) de dejarse abarcar por el entendimiento, pues de lo contrario estaríamos irremediablemente condenados a extraviarnos en ella. La aparición del Systema Naturae de Linneo en 1758 demuestra sin embargo que la naturaleza nos da la razón cuando asumimos que es posible remontarse de sus formas más particulares a las más generales de los géneros y especies hasta formar un sistema jerarquizado completo que abarca todo el reino de lo posible. Por conformidad a fin formal de la naturaleza se entiende la legalidad puramente contingente que el Juicio presume en la disposición favorable de esta a ser conocida. Resulta esencial entender que, al proceder de ese modo, se asume que la naturaleza está organizada técnicamente, como un producto del arte. En modo alguno añade esta conformidad a fin formal un conocimiento teórico de la naturaleza ni ley objetiva alguna sobre su funcionamiento. La técnica de la naturaleza (XX 204) proporciona simplemente el principio que precisa su enjuiciamiento y que nuestro trato con la ella no llega a desmentir. Mediante la conformidad a fin el mundo se presta a ser entendido, a ser leído como el texto compuesto por una voluntad superior con el fin expreso de alcanzarnos como potenciales lectores. Ni se afirma con ello la existencia de ese divino autor ni la del secreto código de su escritura. Únicamente se constata que, para resultar comprensible, la naturaleza debe ser pensada como si pudieran suponerse conceptos, y por tanto fines, para todos y cada uno de los objetos que la comprenden, y como si todos esos conceptos estuvieran a su vez unidos por la existencia de un fin común 5 .

Así pues, Kant reparó en que la posibilidad de subsumir conceptos empíricos de la naturaleza bajo otros más generales hasta alcanzar una comprensión completa y unitaria de la misma (la gesta de Linneo) no podía explicarse solo como resultado de la esquematización de los conceptos del entendimiento en las intuiciones. Entre el insondable abismo de lo empíricamente posible y la cristalización de términos genéricos que confieren orden y sentido a la experiencia debía mediar un proceso que escapaba a las facultades del entendimiento y la razón examinadas en la primera y segunda crítica. Ese oculto nexo subterráneo, que Kant denomina metafóricamente una «desconocida raíz común», se evidenciaría ante todo en la disposición favorable que muestra la naturaleza para adecuarse a nuestro conocimiento por medio del juicio reflexionante. En lugar de limitarse a aplicar las leyes del entendimiento a la experiencia sensible, el juicio

${ }^{5}$ La necesidad de la conformidad a fin como principio a priori del Juicio puede de hecho ser interpretada como prueba de la limitación del entendimiento humano, que solo suponiendo un fin supremo que escapa a su ámbito de conocimiento puede llegar a pensar el conjunto de la naturaleza (Deleuze 109). 
reflexionante infiere esas leyes mediante la contraposición entre representaciones $(X X 213)^{6}$. Se trata en definitiva de asegurar un espacio para el juicio que escape a la prescripción de las leyes sintetizadoras de la intuición y a la necesidad de que los conceptos sean siempre la traducción directa de una experiencia objetiva. Un espacio por lo tanto donde, como sostiene Lebrun (226-227), el sentido preceda al objeto, de modo que incluso los conceptos artificiales de la clasificación posean una cierta objetividad. En la contemplación de la naturaleza el hombre asume que puede encontrar conceptos para su infinita variedad de formas y por lo tanto leyes que la hagan comprensible y abarcable para el entendimiento, lo que lleva a Kant a ver en la técnica de la naturaleza entendida como su conformidad a fin formal el principio trascendental del juicio reflexionante.

Acto seguido Kant repara en que determinadas formas naturales como los organismos vivos o los cristales de hielo se presentan de tal modo a nuestro Juicio que necesitan ser también pensadas como si hubieran sido concebidas para un fin, Como termina de aclarar en la "Dialéctica del juicio estético», al distinguir entre el realismo y el idealismo de la conformidad a fin, todos estos fenómenos de la naturaleza (al igual que las formas bellas) admiten desde luego una explicación conforme a leyes mecánicas, por lo que en modo alguno quiere darse a entender que su diseńo obedezca en verdad al propósito específico de una voluntad. Sin embargo, su disposición interna exige que sean juzgadas como sistemas, poniendo «una idea de ellas como fundamento de su posibilidad» (XX 217). La conformidad a fin que revelan estos particulares objetos (y que Kant denomina real por oposición a la lógica que evidencia la especificación de la naturaleza en géneros y especies) demuestra que la técnica de la naturaleza puede también ser reconocida en sus productos. Al concretar las dos formas en que ello se produce Kant establece la distinción entre los dos tipos de juicio reflexionante. En primer lugar la conformidad a fin se manifiesta en la correspondencia entre la aprehensión imaginativa y la exposición conceptual que hace posible todo juicio sobre un objeto empírico (XX 220). La relación que imaginación y entendimiento mantienen en el Juicio es comparada con la que establecen en la contemplación de un objeto particular sin llegar a producir un concepto de este. Desde el momento en que se da solo para el Juicio, la conformidad a fin del objeto es subjetiva y al

6 En la «Deducción trascendental» la Crítica de la razón pura concede una clara autonomía y un papel productivo (y no solo reproductivo) a la imaginación, en la medida en que sintetiza representaciones no expuestas directamente a los sentidos, proporcionando así la base para toda la actividad de la experiencia (IV 78). Es en la edición modificada de 1787 donde la imaginación sacrifica esa potencialidad e independencia para quedar supeditada al entendimiento como elemento mediador que transmite sus principios a través de la actividad esquematizadora (III 130). 
juicio que de ella resulta se denomina estético. Si en cambio el juicio del objeto implica conceptos empíricos que se comparan con la razón y la posibilidad de un sistema estaremos hablando de un juicio teleológico y una conformidad a fin objetiva (XX 221). El juicio teleológico no sostiene que la idea de fin atribuida al fenómeno natural determine su realidad material, pero en la medida en que vincula la percepción de un objeto a un determinado concepto sí debe considerarse, a diferencia del estético, un juicio de conocimiento ${ }^{7}$.

Desde el punto de partida que proporciona la conformidad a fin formal como principio trascendental del juicio reflexionante empieza a aclararse la unidad de la tercera crítica y el vínculo entre el juicio estético y el teleológico (Bartuschat 235-237). En el primero la forma del objeto propicia en el sujeto la correspondencia de facultades que hace posible el mero conocimiento o conocimiento como tal (überhaupt), la pura posibilidad de remisión de lo particular a lo general que se evidencia en el sentimiento de placer. La exigencia de común acuerdo o universalidad que le acompaña se basa en que, aun tratándose de un juicio subjetivo que nada sostiene sobre la realidad del objeto, parte de un acuerdo entre las facultades que es atribuible a todos los hombres. Frente al estético, el juicio teleológico sobrepasa la esfera subjetiva del juicio al situar un concepto como fin del objeto. No se trata sin embargo de un juicio objetivo, pues no presume que el fin atribuido al objeto sea necesariamente real, pero sí lógico desde el momento en que orienta la forma del objeto a una determinación conceptual. Esta conformidad a fin teleológica es adjudicada tanto a objetos de la naturaleza como del arte; en el primer caso los fines son ideas que se aplican como principios regulativos para hacer posible un conocimiento completo de la naturaleza, en el segundo en cambio responden a la concreción de un propósito real que va implícito en la actividad artístico-técnica. Ambos usos mantienen una relación de analogía: el juicio postula fines en la naturaleza como si esta fuera un objeto de arte concebido por un entendimiento superior. No es que la naturaleza imite al arte, como sostendrán las corrientes románticas y simbolistas del siglo XIX, pues en ningún momento se pretende que las leyes mecánicas de la naturaleza obedezcan realmente a un patrón artístico. Los fines que el juicio teleológico

7 No existe unanimidad en la crítica especializada acerca de si la primera introducción define el principio a priori de la conformidad a fin con suficiente claridad como para fundamentar la autonomía del juicio y la unidad entre las dos partes de la obra (Bartuschat 231; Peter 58-69). La segunda "Introducción" expone en todo caso desde un principio con mayor rotundidad que el sentimiento de placer está ligado a la posibilidad de acuerdo entre imaginación y entendimiento y que la finalidad formal demuestra cómo el juicio se proporciona a sí mismo un principio trascendental independiente de la razón. 
presupone en la naturaleza son ideas de la razón que acompañan la labor del investigador proporcionándole un vector de dirección, un marco situacional sin el cual su trabajo carecería de sentido ${ }^{8}$. También nuestra contemplación del mundo está mediatizada por la postulación de finalidades extraídas de un modelo artístico. Cuando, tiempo después de concluido su relato, Matías Pascal descubre leyendo el periódico que su inverosímil aventura se ha repetido en un suceso local, no interpreta por ello que la realidad haya reproducido intencionalmente su historia, pero tampoco puede ya dejar de juzgar la noticia a la luz de la novela que él mismo ha protagonizado.

La nota del apartado séptimo ("De la estética de la facultad de enjuiciar») contiene un extenso comentario sobre el concepto de perfección (Vollendung) de importantes consecuencias para la traslación de la conformidad a fin al juicio de creaciones artístico-poéticas. La conformidad a fin subjetiva del juicio estético proporciona como acabamos de ver las condiciones que dan lugar a todo juicio de conocimiento empírico sin llegar sin embargo a constituir uno al no atribuir concepto alguno al objeto. Su fundamento es la sensación de placer que suscita el libre acuerdo entre facultades, que a su vez se diferencia de la mera sensación placentera producida por el objeto empírico en el juicio estético sensorial. Kant insiste en que la perfección es enteramente independiente de la sensación de placer por cuanto presume siempre el concepto de algo como fin que orienta el juicio del objeto (XX 228). Por fin se entiende aquí la concordancia de lo múltiple en un todo unitario que debe anteponerse al objeto para poder juzgarlo. No en vano, el ejemplo que ilustra su aserto es el hexágono, donde la convergencia de seis líneas en un plano presupone la adecuación a una finalidad de una figura cuyo hallazgo en una isla desierta nos ocupará un poco más adelante. La perfección es indisociable tanto de la conformidad a fin interna que presume el juicio de figuras geométricas u organismos naturales, como de la práctica que acompaña al de los productos humanos. Sólo en la segunda «Introducción» llega a formularse esta forma de conformidad a fin propia de los objetos artísticos, donde el fin no sólo se presume como principio necesario para entender el objeto, sino que se predica como inevitable consecuencia de la voluntad que lo ha llevado a término

8 En consecuencia la «Crítica del juicio teleológico» no tiene por objeto una teoría sobre la naturaleza orgánica, sino que pretende mostrar cómo nuestra comprensión de los organismos se traslada de la causalidad mecánica a la producción técnica y de los sensible a lo suprasensible mediante el principio de la conformidad a fin para poder asumir un concepto general extrapolable al conjunto de la naturaleza (Joachim Peter 85 y ss.). 
(V 181)9. Y ya en la "Crítica del juicio teleológico» se habla de una conformidad a fin empírica y real de los productos de arte ejemplificada con la jardinería $(\mathrm{V} 364)^{10}$. Todo acto ejecutado con un propósito se deja medir por el grado en que este llega a realizarse, lo que a la postre hace depender su enjuiciamiento de la razón.

La tajante separación entre el concepto de perfección y el sentimiento de placer y displacer que está en la base del juicio estético reflexionante se mantiene también en los productos de las bellas artes. La perfección reaparece como es sabido en el tercer momento de la "Analítica del juicio estético» a propósito de la oposición entre belleza pura y belleza adherente. Kant denomina belleza adherente (anhängende) a la que se expresa por medio del concepto que va ligado a un objeto y al modelo de perfección que este le impone (V 231). Aunque la definición de lo bello responda a una convención cultural y no pueda ser estipulada a priori, existe una universal tendencia en el hombre a establecer modelos de belleza en el juicio de la naturaleza y el arte. Esos modelos no hacen otra cosa que traducir al lenguaje de lo sensible las ideas que la razón se forma sobre la plena realización de un concepto. La imaginación fija los modelos de belleza seleccionando el punto medio entre las representaciones más extremas de un objeto, la imagen-tipo que descarta las anomalías y desviaciones en beneficio del ejemplo arquetípico. Junto a las ideas sobre el modelo de perfección que corresponde al género de un objeto, Kant sitúa el supremo ideal de belleza en el único objeto que permite la representación sensible de las ideas morales, el hombre ${ }^{11}$. Las ideas sobre lo bello abundan en la necesaria impureza de la belleza artística, donde la intervención del autor implica la asunción de un concepto determinado y de su consiguiente modelo de perfección. Un soneto, una crónica de la batalla de Farsalia o una indagación sobre la culpabilidad imponen al artista la tarea de una ejecución que se ajuste al fin reclamado en cada caso por el concepto, lo

9 En la segunda «Introducción» esta conformidad a fin práctica se distingue de la formal subjetiva (como correspondencia de la aprehensión formal del objeto con las facultades del conocimiento que precede a la determinación conceptual) y de la objetiva (como correspondencia de la forma del objeto con la posibilidad del objeto mismo, según un concepto que lo precede y es su condición).

${ }_{10}$ Que aquí se contrapone, dentro de la conformidad a fin objetiva, a la intelectual formal de las figuras geométricas, y a la material de la que es en verdad la que se ocupa de la teleología natural.

${ }_{11}$ No puede negarse que, tal y como se plantean en el problemático $₫ 17$, las ideas genéricas y el ideal de belleza hacen una clara concesión al clasicismo de Winckelmann: para prevenirse contra los desvaríos de la fantasía la razón presume como objetivo de perfectibilidad artística un modelo de proporción y mesura (Lebrun, 355-6). 
que enturbia la conformidad a fin subjetiva del juicio estético que recae sobre el texto. Kant insiste no obstante que la satisfacción intelectual procurada por la realización del modelo no afecta en nada a la sensación que transmite la forma bella: «ni la perfección gana por la belleza ni la belleza por la perfección» (V 231).

\section{El hexágono de Aristipo}

La compleja condición de la obra de arte bella como producto técnico sujeto a una conformidad a fin práctica y como objeto bello capaz de suscitar un juicio estético reflexionante y de ajustarse por tanto a una conformidad a fin subjetiva no termina de articularse hasta la «Deducción del juicio estético». Constatamos allí ( $\$ 45-46)$ que, si bien la creación artística queda siempre sujeta al arbitrio del autor que aplica un saber en forma de normas para alcanzar un fin específico, cuando ese autor es un genio está en su mano conferir al producto de artificio la apariencia de lo natural y con ello también del particular sentimiento placentero que este es capaz de suscitar, y que tan poco tiene en común con la sensación de lo agradable propia del arte "culinario». Así pues, el producto de las bellas artes logra trascender su condición de artefacto desde el momento en que provoca la ilusión de la belleza natural y de la conformidad a fin sin determinación conceptual que esta procura (V 306-307). El arte es ante todo bello cuando consigue borrar las marcas de su ejecución, cuando por lo tanto parece naturaleza, al contrario de lo que sucede con la belleza natural, que lo es mientras produce la ilusión de ser arte. No por ello llega sin embargo el arte a suprimir la conciencia de que el objeto juzgado es el más o menos calculado resultado de una operación volitiva, e incluso de las técnicas destinadas a tal efecto cuando el destinatario atesora las debidas competencias (V 307). El genio lo es por lo tanto en la medida en que logra hacer pasar por conformidad a fin subjetiva lo que quien juzga la obra sabe que solo puede responder a un fin intencionado. En virtud de esa intención el producto de arte tendrá necesariamente el componente «impuro» de la belleza adherente que liga la forma del objeto a un modelo de perfección independiente del sentimiento de placer $^{12}$.

12 La forma es la unidad de enlace entre las partes de una representación $(\$ 14)$, teniendo en cuanta que la imaginación es la encargada de aprehender y sintetizar las intuiciones para que el entendimiento determine su sentido conceptualmente. En el juicio de gusto el segundo momento falta, quedando el juicio de conocimiento reducido a la forma de la finalidad. La forma no debe en todo caso confundirse con su representación visible, que Kant denomina imagen o figura $(B i l d)$. Frente al dualismo cartesiano o la estética de Baumgarten la forma no es tampoco una pálida sombra de la cosa en sí, sino nuestra única forma de acceso a ella (Uehling 74-94). 
La diferente actitud que presume el juicio de un producto de arte y el de una forma natural se hace patente en un célebre ejemplo de la "Crítica del juicio teleológico». Se trata del hallazgo en una isla desierta de una forma hexagonal, una figura que, como ya se ha mencionado, exige una idea de fin como fundamento de su posibilidad. Aunque la fuente no se menciona la anécdota invocada es con toda probabilidad el naufragio del filósofo Aristipo en las playas de Rodas tal y como es referido por Vitruvio en el «Proemio» al libro sexto de la Arquitectura (136). Para Vitruvio el ejemplo de Aristipo demuestra que el hombre sabio encuentra su morada en todas partes, pues apenas encuentra la figura geométrica dibujada en la arena comprende que la isla se encuentra habitada y se encamina directamente al gimnasio de Rodas para disputar allí con otros filósofos. Kant invoca este supuesto en el $\$ 64$ tan solo para ilustrar que determinadas formas de la naturaleza demandan un concepto de la razón para ser juzgadas. La figura geométrica invita a pensar en la intervención de una voluntad que ha diseñado su forma, pues nuestro entendimiento se rebela contra la idea de que las leyes mecánicas hayan propiciado esa coincidencia de lo diverso en un todo unitario (V 370). Pero lo cierto es que numerosas manifestaciones de la naturaleza como el árbol y los organismos en general atestiguan esa misma conformidad a fin interna donde el objeto juzgado presume la idea de su causa y fin (\$ 65-66). Ahora bien, es evidente que el hipotético náufrago de Kant deducirá al instante, como lo hace Aristipo, que la isla no está o no ha estado tan desierta como parece, mientras que la observación de una forma orgánica o un cristal de hielo no conducirá forzosamente a la conclusión de que una particular voluntad lo ha concebido y llevado a cabo. La obra artístico-poética asume de entrada que, como la figura geométrica, debe ser juzgada conforme a un fin aunque su militancia en el campo de las artes libres le permite aspirar a que su cuidada estructura y ejecución se equiparen a las que la naturaleza evidencia en sus formas más elaboradas.

La problemática en que nos emplaza el juicio de la obra artístico-literaria se entiende mejor si imaginamos por un momento que el hallazgo de una anómala forma natural se produjera en una isla habitada, donde la intervención de la mano humana se contempla de entrada como posible. Edgar Allan Poe explotó las implicaciones de esta incertidumbre como recurso narrativo en el tramo final del viaje que su personaje Arthur Gordon Pym emprende hacia el Polo Sur. Al llegar a la isla de Tsalal, el protagonista y su compañero Peters buscan refugio de los salvajes que la habitan en los angostos precipicios de una cordillera. El narrador describe el trazado de las formaciones montańosas acompañando su texto de gráficos ilustrativos. En uno de los abismos los hombres descubren unas hendiduras en la pared que Peters interpreta como los caracteres de una escritura 
y el dibujo de un perfil humano. Al encontrar en el suelo esquirlas del mismo material el narrador entiende en cambio que un temblor ha debido provocar su desprendimiento y los surcos tienen por lo tanto una causa natural. Sólo después de llegar al abrupto final de la novela, una nota de su fingido editor desvelará la verdad que ocultan estos fenómenos: los surcos de la pared guardan un evidente parecido con caracteres arábigos y egipcios que en sus respectivas lenguas rezan «ser blanco" y «región del sur». En cuanto a los cuatro precipicios recorridos por los protagonistas, su trazado compone otras tantas letras de una palabra en etíope que significa "estar en sombras». Revelando como obra humana, o al menos como obra de una voluntad (y no de otro modo entiende Kant el arte), lo que el viajero explorador veía como fortuita formación de la naturaleza, el autor reclama para estos signos una finalidad. Pero, curiosamente, esta no es tanto práctica como estética, pues remite al «secreto argumento» de la novela: «el temor y la vilificación de lo blanco» (Borges 71-79), una misteriosa urdimbre poética que discurre paralela a las tribulaciones marítimas de Gordon Pym. Los sucesos que jalonan las aventuras del protagonista repiten sin aparente vínculo causal motivos de colores o de la ausencia de color. Su causalidad interna no es otra que la de la magia, el «juego preciso de vigilancias, y afinidades» que a juicio de Borges constituye el problema fundamental de toda novela. De este modo, la exploración de la isla nos ha llevado de la conformidad a fin subjetiva que el juicio teleológico atribuye a los productos naturales, a través de la objetiva que cabe conceder a las creaciones del hombre, hasta la suma de ambas que resulta cuando estas se juzgan como obras de arte bellas. La isla de Tsalal y su orografía se convierten así en símil de la superficie del texto poético, donde la obra del genio borra la distinción entre artificio y naturaleza ${ }^{13}$.

\section{EI fin de la narración}

La isla de Poe permite ilustrar cómo la Crítica del Juicio sitúa las obras de arte (y desde luego las literarias) en un terreno ambivalente con respecto a la idea de conformidad a fin. El objeto artístico obedece al fin práctico que una voluntad

13 Borges se detiene en otro pasaje donde la naturaleza es también portadora de una poética de los colores, cuando describe el misterioso caudal de agua que cambia de tono en función del movimiento, llegando en estado de reposo a separarse en vetas claramente delimitadas. La manifestación natural no se presenta simplemente bajo la apariencia de la conformidad a fin sin fin del juicio estético en la belleza natural, sino de la conformidad a fin propia del juicio estético-artístico (solo relacionando el motivo de los colores en sus diferentes representaciones cobran estas un sentido que no es conceptualmente determinable). 
se propone alcanzar mediante la aplicación de conocimientos técnicos adquiridos, siendo esta forma de conformidad a fin la que se traslada por analogía a la naturaleza en los juicios teleológicos. Como se recuerda en el $\$ 48$, «...cuando el objeto es dado como un producto del arte, y como tal debe ser declarado bello, debe entonces, ante todo, ponerse a su base un concepto de lo que deba ser la cosa, porque el arte siempre presupone un fin en la causa» (V 311). Pero si en efecto el objeto de arte produce la belleza que evidencia el sentimiento de placer suscita además un juicio estético, sustrayéndose a la determinación del concepto y promoviendo el libre juego entre las facultades. La diferencia entre las dos modalidades de conformidad a fin se pone de manifiesto en la relación que ambas establecen entre objeto y concepto, teniendo en cuenta que Kant entiende por fin «el concepto de un objeto en cuanto encierra al mismo tiempo la base de la realidad de ese objeto» (V 180). Pero esa diferencia no se solventa sencillamente afirmando que la conformidad a fin subjetiva prescinde de toda determinación conceptual, pues sabemos que, a diferencia de lo que sucede con la belleza natural, el concepto de un fin no está nunca ausente de la belleza artística. En función de los temas que aborda, los referentes que trata, o las tradiciones literarias que adopta, el texto es juzgado conforme a diversos conceptos y a los modelos de perfección que estos comportan. La duda que resta por aclarar es si la narración, por el hecho de serlo, busca también la adecuación a un fin determinado.

Tanto Matías Pascal como Arthur Gordon Pym deben afrontar el desafío de referir la historia de una vida que se antoja escasamente creíble. Si el segundo es testigo de hechos tan brutales como fabulosos en su viaje al confín del mundo, el personaje de Pirandello da cuenta de los sucesos que se encadenan para dar lugar a sus dos muertes. Ambos personajes asumen así un punto de enunciación imposible (el Polo Sur y la muerte) que inevitablemente problematiza la credibilidad del relato referido. En estas circunstancias, solo una fe incondicional en las posibilidades del medio escogido podría justificar al acto comunicativo del que participa el texto. La voluntad de representar la unidad de sentido referida a una vivencia temporal es en efecto el rasgo consustancial de la narración que explica su éxito en la génesis de la modernidad, cuando el sujeto se convierte en el centro de interés artístico al tiempo que se problematiza su realidad y cuestionan sus límites. Mas ello equivale a afirmar que la narración se plantea como objetivo la traslación de aquello que faculta al entendimiento para anticipar que la naturaleza responderá a su designio ordenador: el vínculo entre la unidad de la experiencia conforme a leyes trascendentales y de la experiencia como sistema de conocimientos empíricos que solo la conformidad a fin formal hace posible (XX 208). Que el mundo recreado en el texto literario se deje organizar de 
acuerdo a un fin último no puede sorprendernos evidentemente como lo hace la adecuación de la naturaleza a los conceptos de la razón. Pero antes que una imagen del mundo (como la cosmogonía dantesca, la del orbe terrestre en forma de crucifijo que se despliega en La vida de Aleixandre, la que resulta de los Autos Sacramentales o, en una órbita más contemporánea, la cosmogonía romántica de Huidobro en Cántico) lo que la narración representa es el modo en que es conocido a través de la experiencia, como contingente unidad de sentido de los fenómenos empíricos. Así, si el juicio de la naturaleza parte de la conformidad a fin formal y el del texto literario conjuga la conformidad a fin subjetiva del juicio estético con la objetiva de la belleza adherente, en el caso del relato se da la circunstancia de que el concepto de fin que esta última presupone es la propia conformidad a fin de la naturaleza.

En su Farolillosofía, Paleari, el maestro en teosofía que ilustra al difunto Matías Pascal, presenta al individuo como un insignificante farol que ilumina la negra inmensidad hostil de lo desconocido con la luz de su credo o convicción individual. Cada cierto tiempo un embate histórico apaga la llama de los faroles sumiendo a los hombres en la oscuridad antes de que sustituyan su luz por una de otro color. Desde una óptica kantiana diríamos que el entendimiento no podrá nunca demostrar si el universo responde en sus últimas causas a la imagen que el farolillo le atribuye (esa distancia insalvable entre el noúmeno y las humanas lentes de colores que angustiaba al joven Kleist leyendo a Kant), pero lo asombroso en sí mismo es que el entendimiento llegue a encontrar una correspondencia a los conceptos de la razón en el insondable material intuitivo, y que esta ilumine con sus ideas el mundo en su conjunto confiriéndole orden y sentido. El desafío de la narración consiste en provocar un asombro equivalente partiendo sin embargo de un sustrato artificial: allí donde el lector solo debiera aguardar la medida planificación del producto técnico juzga el texto como si la multiplicidad de sus representaciones se ajustara casualmente a una pauta organizadora. La validez de esta premisa no está ligada a una mera «ilusión de realidad», sino al nexo configurador que hace posible como tal el relato: el fin último que el Juicio asigna a la naturaleza para que se ajuste a la posibilidad de la experiencia. Una novela como El difunto Matías Pascal puede juzgarse sobre la base de diversos conceptos pero, como relato, el texto de Pirandello aspira antes que nada a reflejar el proceder del juicio reflexionante en la subsunción de fenómenos naturales bajo el concepto aglutinador que presupone la unidad de experiencia. Del mismo modo, la comprensión de un texto se inicia con el reconocimiento de marcos situacionales que permiten relacionar la materia diegética con el archivo sedimentado en la memoria del lector. La imaginación procede 
conforme a la lógica del juicio determinante esquematizando conceptos para las imágenes representadas, y si ese procedimiento incorpora conceptos vinculados a la institución literaria (géneros, tropos, motivos, formas...), el texto será identificado como un producto poético (Hogan 83-92) ${ }^{14}$. Pero en el caso del relato el juicio necesita además asumir la adecuación de la representación artística en su conjunto a la unidad de experiencia presupuesta por la propia configuración narrativa. Desde Los años de aprendizaje de Wilhelm Meister de Goethe hasta El innombrable de Samuel Beckett, el relato asume la necesidad de esa correspondencia para reproducirla en el horizonte del lector, donde se actualiza permanentemente el principio trascendental que propicia el enlace entre intuición y concepto y la adecuación de una naturaleza salvaje a las ideas de la razón. Sin necesidad de recurrir a una genealogía de la narración, su historia en la literatura moderna corre al albur del vuelco antropocéntrico que convierte al hombre en único testigo y explorador de la creación. Entendemos así en todo su alcance la duda inicial de Matías Pascal, pues solo asumiendo la posible adecuación del universo a las ideas de la razón puede el relato aspirar a recrearla. El destino de la narración es ante todo peculiar porque el giro copernicano que propicia su fortuna es al mismo tiempo lo que anticipa su problematización como forma representativa instalada en una crisis crónica.

La coincidencia entre la conformidad a fin formal de la naturaleza y lo que hemos definido como fin consustancial a la narración no puede ignorar sin embargo la principal motivación de Kant a la hora de proponer con el principio de conformidad a fin un nexo entre las facultades del conocimiento. La habilitación de la naturaleza como terreno abarcable por la razón responde ante todo a la necesidad de demostrar que esta puede interceder en el terreno de lo fenoménico para hacer valer su derecho. Solo anticipando la adecuación de la naturaleza a un sistema de fines puede la razón conducirse en un universo de las impresiones que de lo contrario resultaría impredeciblemente caótico y por ende hostil a todas sus exigencias. El principio de conformidad a fin tiende en definitiva el puente para que la ideas desplieguen su influjo sobre el terreno de la experiencia sin recaer en el dogmatismo de la metafísica tradicional. Kant separa esta disciplina de los conocimientos teóricos con el objeto de que ciertos conceptos puedan preservar su legitimidad ateniéndose a un uso apropiado (Lebrun 504 y ss.): no es preciso sostener que la creación está sujeta al plan de una voluntad suprema para asu-

${ }^{14}$ La ciencia cognitiva ha unido en los últimos tiempos esfuerzos con la teoría literaria para tratar de describir los procesos asociativos que intervienen en la experiencia lectora permitiendo primero la comprensión del texto y luego su interpretación. 
mir que la experiencia se deja sujetar a los conceptos de la razón o, lo que es lo mismo, que responde al empeño de la actividad reflexiva. La reiteración de este supuesto en el entorno ficcional del relato tendrá necesariamente consecuencias sobre el quehacer narrativo como entorno donde se desarrollan en todo su alcance las implicaciones de un conocimiento práctico.

\section{Referencias bibliográficas}

Bartuschat, Wolfgang (1972). Zum systematischen Ort von Kants Kritik der Urteilskraft. Frankfurt am Main: Klostermann.

Borges, Jorge Luis (1976). Discusión. Madrid: Alianza.

Deleuze, Gilles (1997). La filosofía crítia de Kant. Madrid: Cátedra.

Dumouchel, Daniel (1997). Kant et la genèse de la subjectivité esthétique. Paris: Vrin.

— «Genése de la Troisème Critique: le rôle de l'esthetique dans l'achèvement du système critique». Kants Ästhetik. Kant's Aesthetics. L'esthétique de Kant. Ed. Parret, Hermann. Berlín-Nueva York: de Gruyter, pp. 18-40.

Duque, Félix (1998). Historia de la Filosofia Moderna. La era de la crítica. Madrid: Akal.

Hogan, Patrick Colm (2003). Cognitive Science, Literature and the arts. New York: Routledge.

Klemme, Heiner F. (2009). Kritik der Urteilskraft. Hamburg: Meiner.

Kuyters, K. (1972). Kants Kunsttheorie und die Einheit der Kritik der Urteilskraft, Amsterdam: North Holland Publishing Company.

Lebrun, Gérard (2008). Kant y el final de la metafísica. Madrid: Esolar y mayo.

LujÁn, Silvia (2010). Arte y naturaleza. Buenos Aires: Ediciones del signo.

Peter, Joachim (1992). Das traszendentale Prinzip der Urteilskraft. Eine Untersuchung zur Funktion und Struktur der reflektierenden Urteillskraft bei Kant. Berlín: de Gruyter.

SÁnchez Madrid, Nuria (2011). Primera Introducción de la Crítica del Juicio. Madrid: Escolar y mayo.

Tonelli, Giorgio (1958). «Von den verschiedenen Bedeutungen des Wortes Zweckmäßigkeit in der Kritik der Urteillskraft», Kant-Studien Vol. 49, pp. 154-166.

Uehling Jr., Theodore E. (1971). The notion of Form in Kant's Critique of Aesthetic Judgement. La Haya: Mouton. 
Vitruvio (1992). Los diez libros de arquitetura. Madrid: Akal.

Zамmiтo, John M. (1992). The Genesis of Kant's Critique of Judgement. Londres: The University of Chicago Press.

Recibido: 03/11/2013

Aceptado: 27/03/2014 
